\title{
Simulation Based Topology Optimization Assessment with Manufacturing Constraints
}

\author{
Abas Ahmad ${ }^{1 *}$, Muhammad Aamir Raza ${ }^{1}$, Francesca Campana ${ }^{2}$ \\ ${ }^{1}$ Abas Ahmad, Muhammad Aamir Raza (Ph.D.) \\ Researcher: CEASAT \\ Islamabad, Pakistan \\ *engr.abas@gmail.com \\ ${ }^{2}$ Francesca Campana (Ph.D.) \\ Associate Professor \\ Sapienza Universita di Roma \\ Rome, Italy
}

\begin{abstract}
In Automotive and Aerospace industries, Topology Optimization (TO) is being used for the last few decades to produce lightweight structures. On the other hand, TO produces very complex geometrical features (i.e. irregular shape and hidden cavities along the thickness) that is sometimes difficult to be manufactured even with Additive Manufacturing (AM) and Casting techniques. In this paper suitable design and manufacturing constraint (MC) are applied during TO process that act as an Optimization Tool (OT) and improves geometrical features of the mechanical structures for easy manufacturing. Three mechanical structures with different geometries and boundary conditions have been considered for analysis purpose. Topology Optimization based on linear static analysis has been performed using OptiStruct (HyperWorks) solver. Finally, results of analysis conclude that the proposed OT produces lightweight structures with very simple geometries that can easily be manufactured with the help of AM or Casting techniques.
\end{abstract}

Keywords-Topology Optimization, Structural Optimization, Lightweight Design, FEA, Manufacturing Constraints, OptiStruct (HyperWorks) Solver, Linear Static Analysis

\section{INTRODUCTION}

Automotive and Aerospace sectors are continuously striving to improve the comfort level and maximize the space. Resultantly, the structural weight is being increased which causes high fuel consumption, high emissions, dynamic instability and material cost. Therefore, a deliberate effort is being put to produce light weight structures in order to minimize the above mentioned problems [1] [2] [3]. Generally, there are numerous methods such as numerical structural optimization and many commercial solvers to design lightweight structures [4] [5] [6] [7] [8] [9] [10] [11] [12]. For the last few decades, Topology Optimization is being used as an effective and widely acceptable optimization tool to produce lightweight structures [13] [14] [15] [16]. TO is a mathematical iterative optimization algorithm [17] which provides an optimal element density layout within a given set of design space and boundary constraints. Two basic TO theoretical approaches have been developed, the Solid Isotropic Material Penalization (SIMP) and the Multilevel Set Method. SIMP has been implemented in many commercial FEA software, as for example OptiStruct that is included in the HyperWorks suite [18]. SIMP approach is a well known and widely accepted as an efficient technique for TO which discretize the design space in term of element density distribution with value from 0 to 1 . Inside the discretized domain, 1 represent a solid element, 0 represent a void and the intermediate values represent intermediate densities which are penalized by SIMP approach to produce a best shape for manufacturing.

Though, TO propose a lightweight design but on the other hand as a final result it may give a very complex geometry (Irregular shape and hidden cavities along the thickness) which is sometimes even difficult to be manufactured with the help of AM or casting technologies [19]. Applying geometrical constraints able to force manufacturability of the TO result is an interesting option that may support the component fabrication but also a convenient way to force surface regularization after the TO process.

Therefore in this research work, an endeavor has been made to apply density based topology optimization [20] with combination of suitable design and manufacturing constraints [21] [22] [23] [24] using OptiStruct. The aim is to expand the applications of TO as a concept design tool including specific constraints able to avoid unfeasible local or global topologies or features. OptiStruct offers number of Manufacturing Constraints (MC) such as draw, extrusion, symmetry, wall thickness etc to take into account manufacturing features during TO.

Following, three mechanical structures with different geometries and boundary conditions have been analyzed in an order of easier to complex case for the desired research work.

a. General Purpose Bracket (GPB)

b. Engine Bracket (EB)

c. Hinge Bracket (HB) 


\section{METHODOLOGY}

The following sequence (Fig-1) has been followed for the entire analysis and simulations. Each blue block in the sequence defines a specific step and gives distinct outputs, as shown in green.

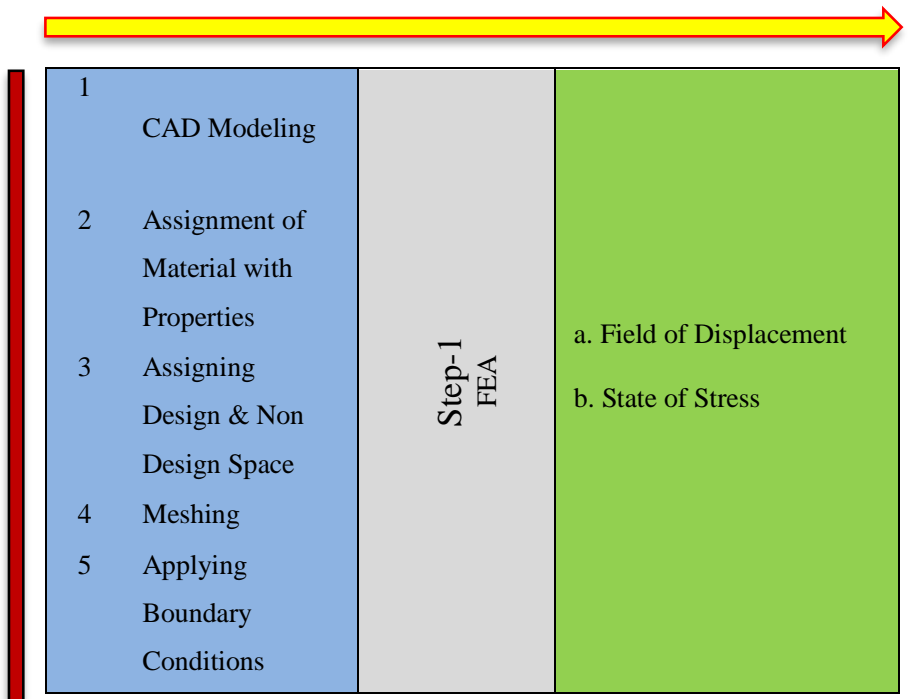

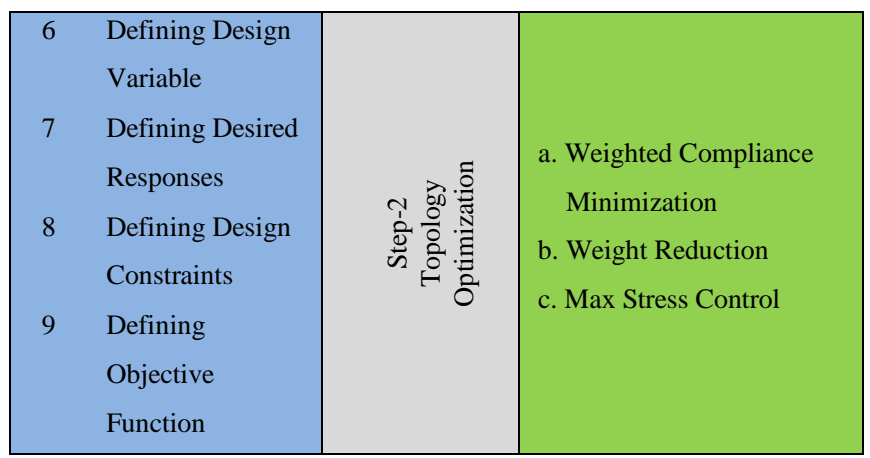

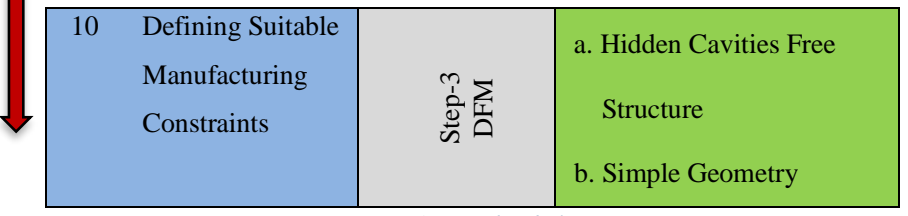

Figure-1. Methodology

\section{FEA MODELING}

\section{A. $\quad$ CAD Modeling}

CAD models of each structure are shown below (Fig-2). Further details are as under:-

GPB: It is a general purpose structure. It is fixed to some support entirely from its back while holes located at front are subjected to a total tensile force of $400 \mathrm{~N}$.

EB: It is mounted to the chassis structure through two holes located at the base while hole at top is supporting the engine weight $(500 \mathrm{~N})$ and also subjected to a braking force of $833.33 \mathrm{~N}$ (Braking is taken as an impulse event within $1 \mathrm{sec}$ with vehicle speed of $60 \mathrm{~km} / \mathrm{h}$ ).

HB: Four holes located at base are supporting weight of the Airplane door $(300 \mathrm{~N})$ while hole at end of the arc length is pivoted to the wall structure to act as a hinge.

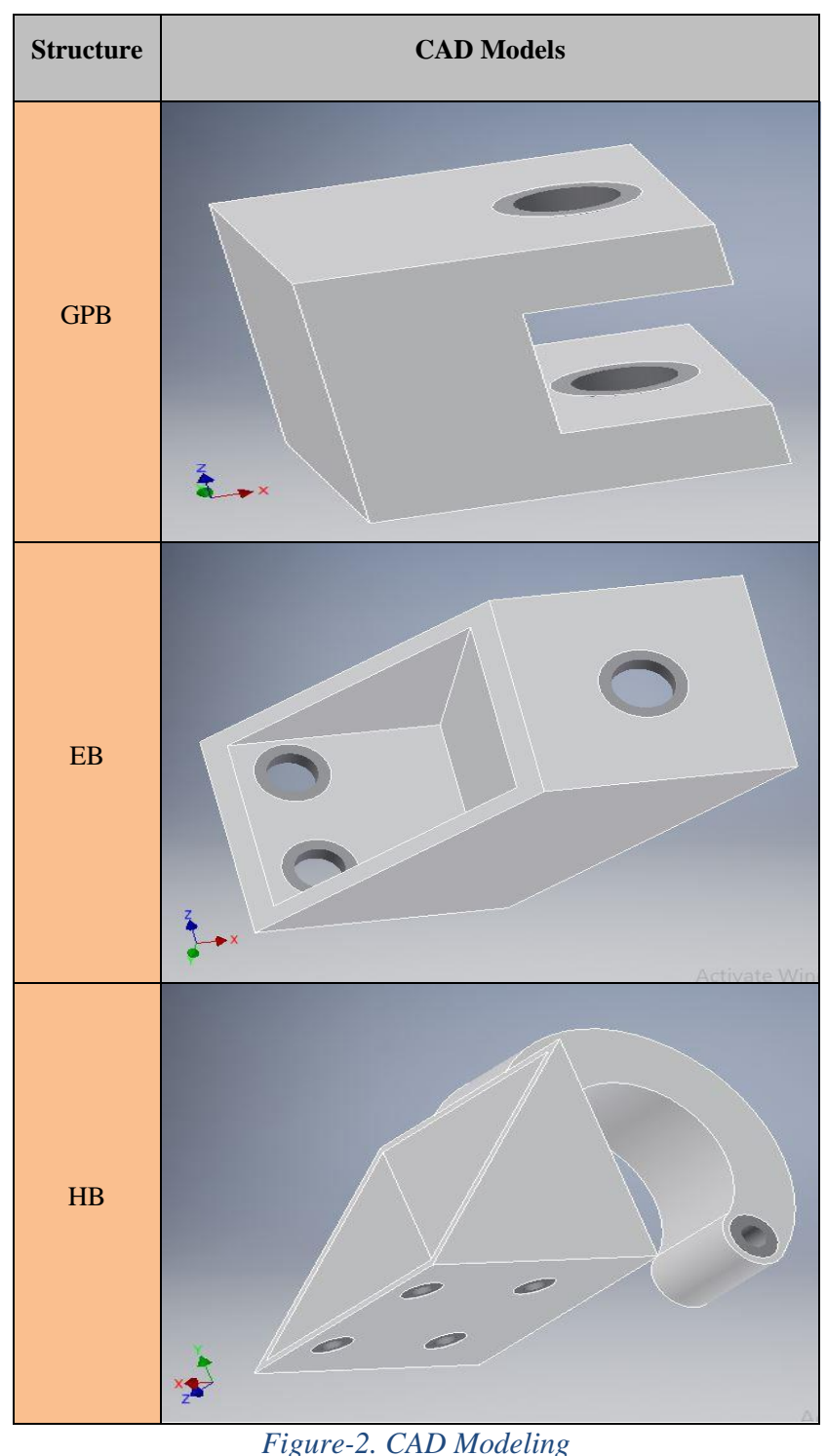

\section{B. $\quad$ Material and Properties}

For FEA modeling, material AISI 4130 Steel has been assigned to all structures with following properties (Table-1) including different mass for each structure. Furthermore, OptiStruct's MAT1 card is used to define isotropic linear material for analysis and unit card is used to facilitate analysis with SI units. 
Table 1. Properties of Material

\begin{tabular}{|c|c|c|}
\hline \multirow{3}{*}{ Mass (M) } & GPB & $0.725(\mathrm{Kg})$ \\
\hline & EB & $0.398(\mathrm{Kg})$ \\
\hline & HB & $2.26(\mathrm{Kg})$ \\
\hline Yield Strength $\left(\mathrm{Y}_{\mathrm{s}}\right)$ & \multicolumn{2}{|c|}{$4.6 \times 10^{8}\left(\mathrm{~N} / \mathrm{m}^{2}\right)$} \\
\hline Young Modulus (E) & \multicolumn{2}{|c|}{$2 \times 10^{11}\left(\mathrm{~N} / \mathrm{m}^{2}\right)$} \\
\hline Poisson Ratio (v) & \multicolumn{2}{|c|}{0.285} \\
\hline Density $(\rho)$ & \multicolumn{2}{|c|}{$7860\left(\mathrm{Kg} / \mathrm{m}^{3}\right)$} \\
\hline
\end{tabular}

\section{Design and Non Design Space}

Design and non-design space play a vital role in topology optimization and therefore have to be defined very carefully because during topology optimization the material is removed only from the design space subjected to low stress concentration while the non-design space is remained the same. Normally the non design space is allocated to the section or area where no changes are required or subjected to boundary conditions.

In our case, section of each structure subjected to boundary conditions is defined as non design space. Furthermore, design and non design spaces for each structure are illustrated in Fig3 , where yellow color represents the design space and blue color represents the non-design space.

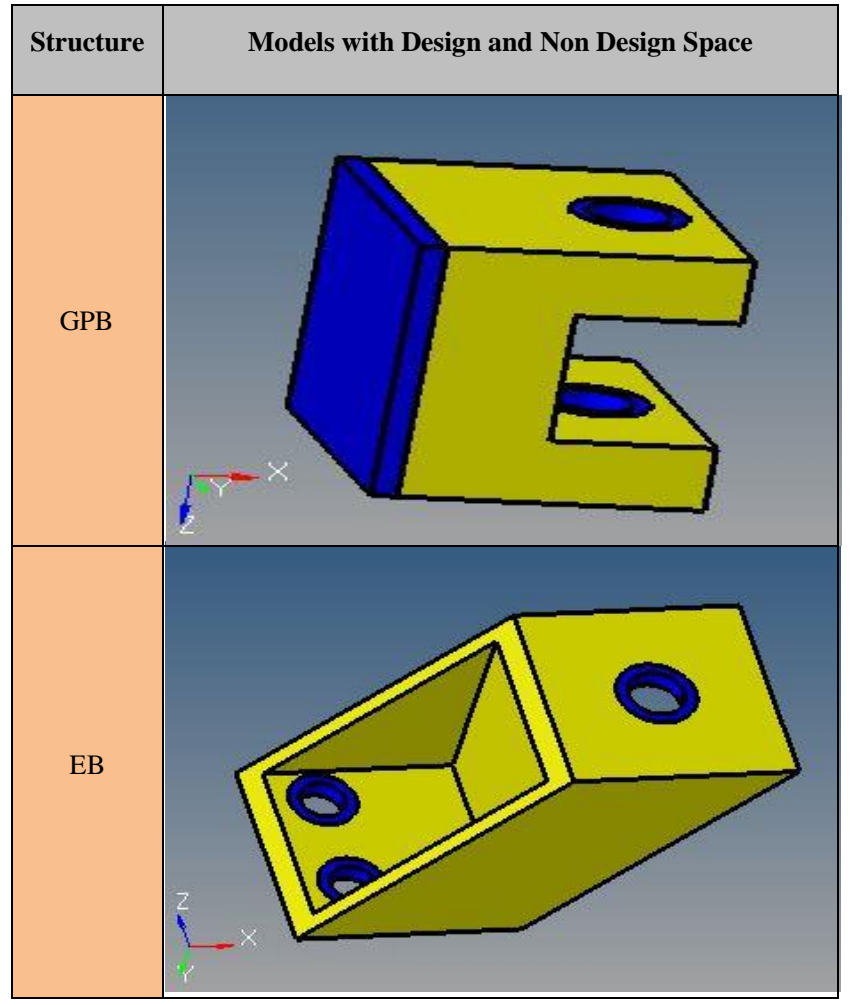

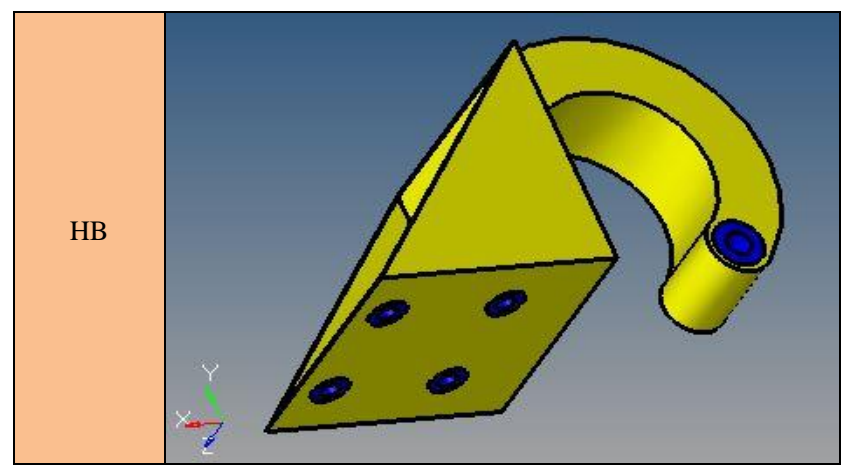

Figure 3. Models with Design and Non Design Space

\section{Meshing and Boundary Conditiuons}

Meshing is carried out in order to reduce degree of freedom from infinite to finite. Loads and constraints are also applied to each structure and then load case for each boundary condition is defined with linear static type in order to carry out linear static analysis. Furthermore, rigid body element (RBE) is defined at all holes in order to distribute the boundary conditions equally on all nodes irrespective of the load position [25] [26]. Details of Meshing and boundary conditions for each structure are shown in Table-2 and Fig-3.

Table 2. Meshing and Boundary Conditions

\begin{tabular}{|c|c|c|c|c|}
\hline \multicolumn{2}{|c|}{ Nomenclature } & GPB & EB & HB \\
\hline Element Size $(\mathrm{mm})$ & $2 \mathrm{D}$ & Trias & Trias & 4 \\
\hline \multirow{2}{*}{ Type of Element } & Trias \\
\cline { 2 - 5 } & 3D & Tetras & Tetras & Tetras \\
\hline \multirow{3}{*}{ Constraints } & $\mathrm{Lx}$ & 0 & 0 & 0 \\
\cline { 2 - 5 } & $\mathrm{Ly}$ & 0 & 0 & 0 \\
\cline { 2 - 5 } Free $=1$ & $\mathrm{Lz}$ & 0 & 0 & 0 \\
\cline { 2 - 5 } & $\mathrm{Rx}$ & 0 & 0 & 0 \\
\cline { 2 - 5 } Fixed =0 & $\mathrm{Ry}$ & 0 & 0 & 0 \\
\cline { 2 - 5 } & $\mathrm{Rz}$ & 1 & 0 & 1 \\
\hline \multirow{3}{*}{ Force (N) } & $\mathrm{Fx}$ & 400 & 0 & 0 \\
\cline { 2 - 5 } & $\mathrm{Fy}$ & 0 & 500 & 0 \\
\cline { 2 - 5 } & $\mathrm{Fz}$ & 0 & 833.33 & 300 \\
\hline
\end{tabular}

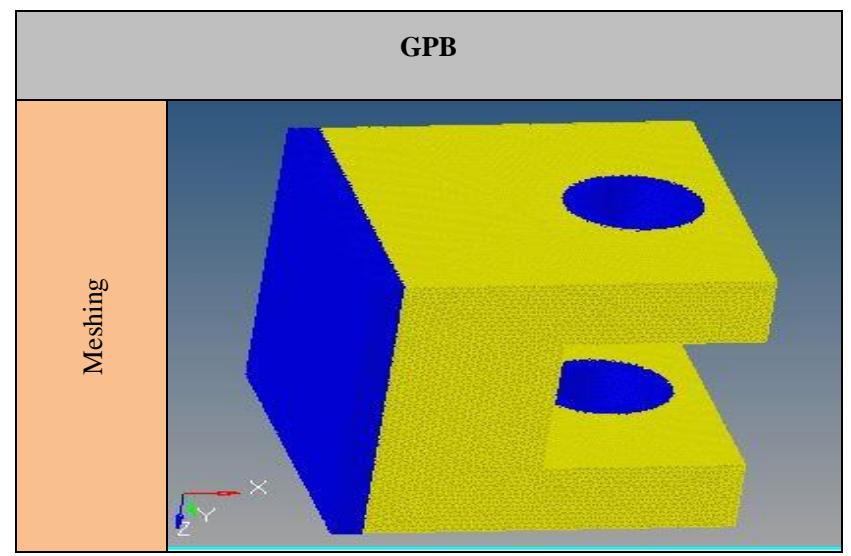




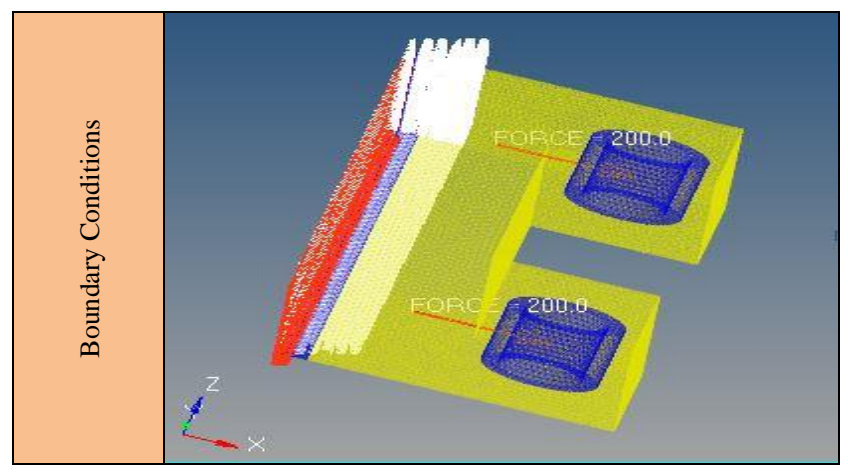

Figure 4. Meshing and Boundary Conditions - GPB

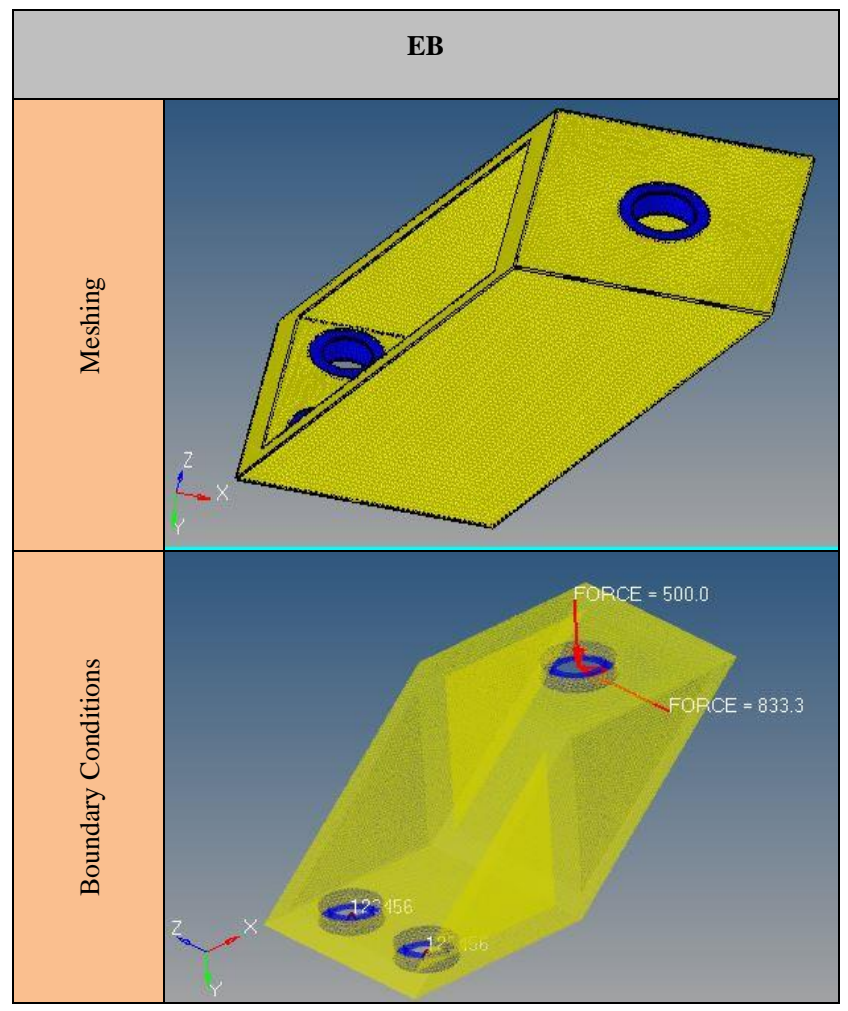

Figure 5. Meshing and Boundary Conditions - EB

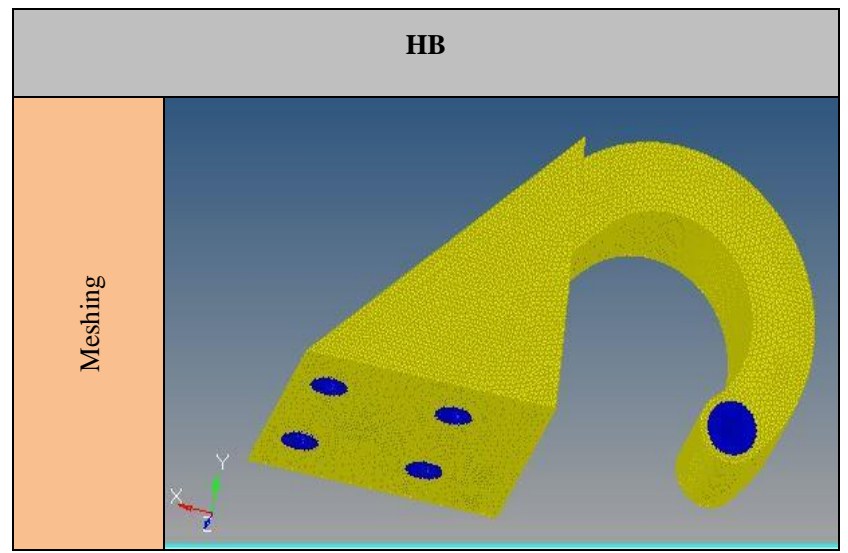

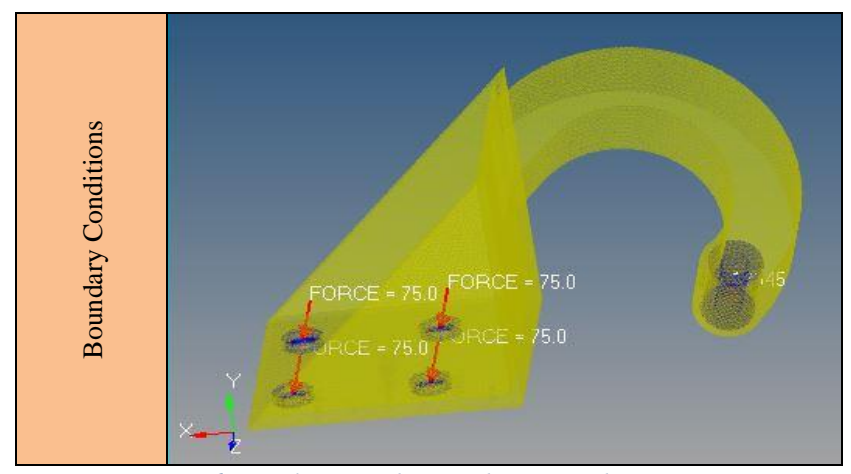

Figure 6. Meshing and Boundary Conditions - $\mathrm{HB}$

\section{TOPOLOGY OPTIMIZATION MODELING}

Following sequence is followed for the entire process of TO.

\section{A. Defining Design Variable}

Due to SIMP approach, element density is defined as design variable to produce optimal element density distribution inside the design space. Furthermore, OptiStruct's psolid card is selected for analysis due to 3D geometry.

\section{B. $\quad$ Defining Desired Responses}

Volume Fraction $\left(\mathrm{V}_{\mathrm{f}}\right)$ is defined as the first global response due to that it considers only design space for analysis. In addition, weighted compliance $\left(\mathrm{W}_{\mathrm{c}}\right)$ is taken as the second design response to accumulate the effect of boundary conditions by introducing OptiStruct's loadsteps card.

\section{Defining Design Constraints}

Considering the aim of lightweight design, $V_{f}$ with upper bound is limited to a value of 0.5 which means the analysis will reduce $50 \%$ of the original $\mathrm{M}$. In addition providing a minimum (min) Factor of Safety (FoS) of 2.5, OptiSturct's Stress Constraint [22] is defined and set to a value of $\mathrm{Y}_{\mathrm{s}} / 2.5$ in order to restrict the max Stress $\left(\delta_{\max }\right)$.

\section{Defining Manufacturing Constraint (MC)}

Keeping in view the geometrical waviness and cavities along the thickness obtained during simple TO, Thickness Constraint (TC) and / or Extrusion Constraints (EC) are used to cater for the above mentioned anomalies respectively. TC actually increases the wall thickness by defining a min dimension of the wall using Optistruct's mindim card and resultantly reduces the surface waviness. Whereas EC is employed based on extrusion path along the section where a constant cross section is required and therefore eliminate the hidden cavities. Therefore, mindim should be set to a value at which fine surface smoothness is obtained and similarly extrusion path be applied wherever there are hidden cavities. Though employment of MC reduce the percentage of weight reduction but it is in fact a tradeoff between lightweight design and smooth / hidden cavity free geometry.

\section{E. Defining Objective Function}

High stiffness is required to obtain a performance structure. Therefore exploiting the concept of compliance theory, 
minimization of weighted compliance is set to objective function to maximize its stiffness against the given loadsteps.

\section{F. Overall Mathematical Model}

Following mathematical model is applied to all structures for desired analysis of TO.

Min $\mathrm{W}_{\mathrm{c}}$ (Weighted Compliance)

$\mathrm{W}_{\mathrm{c}} \in \mathrm{D}, \mathrm{D}$ is the design space

Subject to,

$$
0.5 \leq \mathrm{V}_{\mathrm{f}} \leq 0.8
$$

$\delta_{\max } \leq$ Yield Strength / 2.5

$$
\mathrm{W}_{\mathrm{c}=} \sum_{n=0}^{N} u_{n}^{T} k_{n} u_{n}
$$

Where, $\mathrm{K}$ is the stiffness matrix

$\mathrm{U}$ is the global displacement vector

$\mathrm{u}_{\mathrm{n}}$ is the local displacement at element $\mathrm{n}$

$\mathrm{k}_{\mathrm{n}}$ is the stiffness of element $\mathrm{n}$ obtained through SIMP

i.e. $k_{n}=x_{n}^{P} k_{0}$

Where, $\mathrm{k}_{0}$ id the element density

$\mathrm{P}$ is the penalization factor from $0 \sim 3$. $\mathrm{P}$ at 3 gives the discrete value i.e. either 0 or 1 for the density element.

\section{RESULTS ANS DISCUSSIONS}

In this section, TO without and with Manufacturing Constraints is performed under the given set of boundary conditions and design space for each structure. Subsequent results are discussed with comparison, as given below.

GPB: TO without MC is performed which though gives good results i.e. there is no cavities along the thickness but still surface waviness can be observed at central and outer surfaces (Fig.7). Therefore, there is no need of EC but TC is required to be applied to reduce the surface waviness. Hence TC gives nice results at mindim of $50 \mathrm{~mm}$ with max Von Mises Stress $21.4 \mathrm{~N} / \mathrm{m}^{2}$ (Fig.8). It can also be seen that TC reduce the waviness and therefore increase the overall mas.

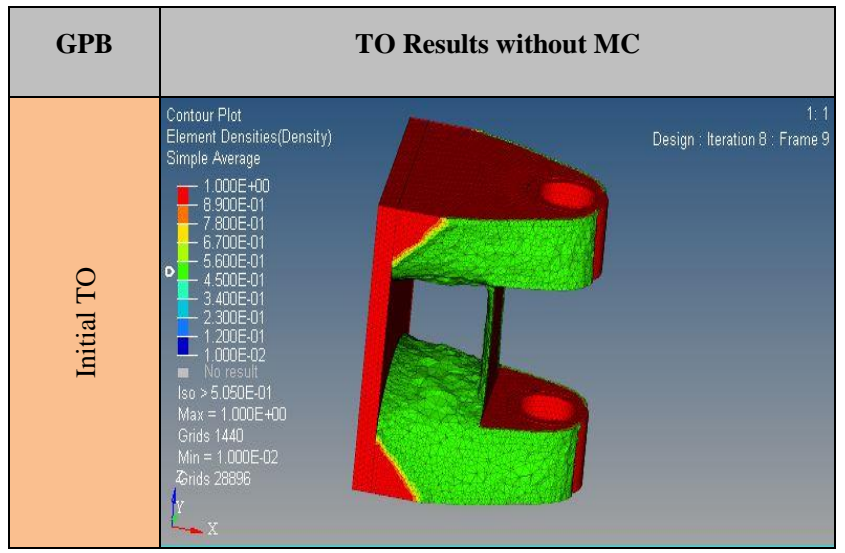

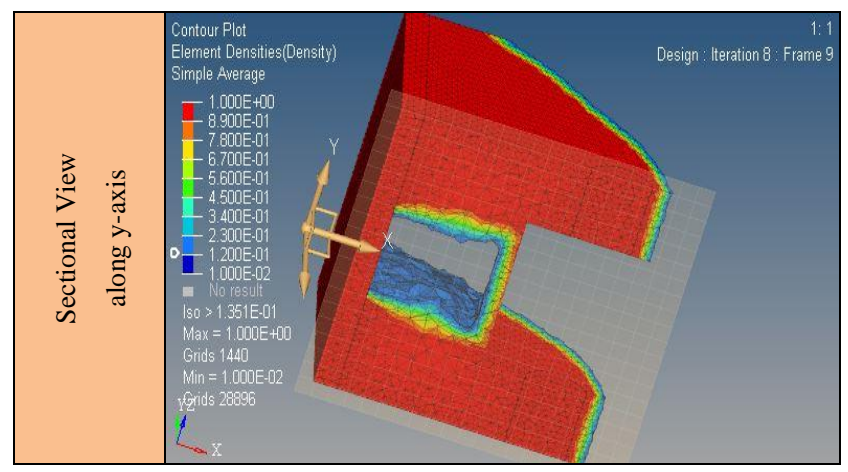

Figure 7. TO without MC - GPB

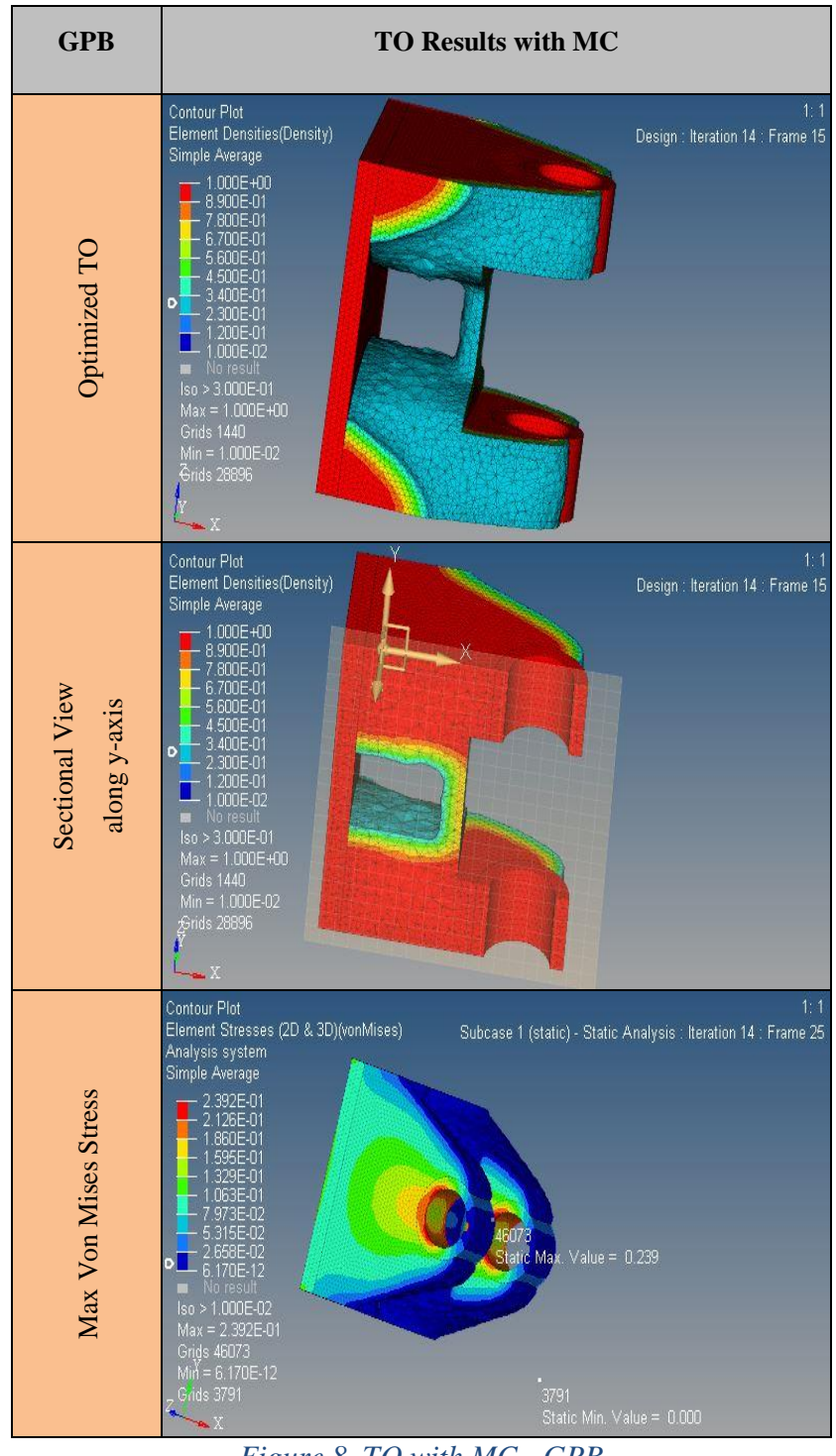

Figure 8. TO with $M C$ - GPB 
EB: TO without $\mathrm{MC}$ shows very poor results i.e. porous and extreme wavy surface at center and side walls. Furthermore, hidden cavities can also be seen along thickness from base to top (Fig.9). Therefore, both TC and EC are required to be applied to fix the aforementioned issues. Mindin of value $25 \mathrm{~mm}$ removes the pours and extreme waviness at surfaces while EC along the given path (Fig.10) limits the cavities and produce a constant cross section. Finally good finishing is achieved along all surfaces with $\max$ Von Mises Stress $97 \mathrm{~N} / \mathrm{m}^{2}$ (Fig.11). It can also be observed that due to employment of TC and EC, slight increment occurred in overall mass of the structure.

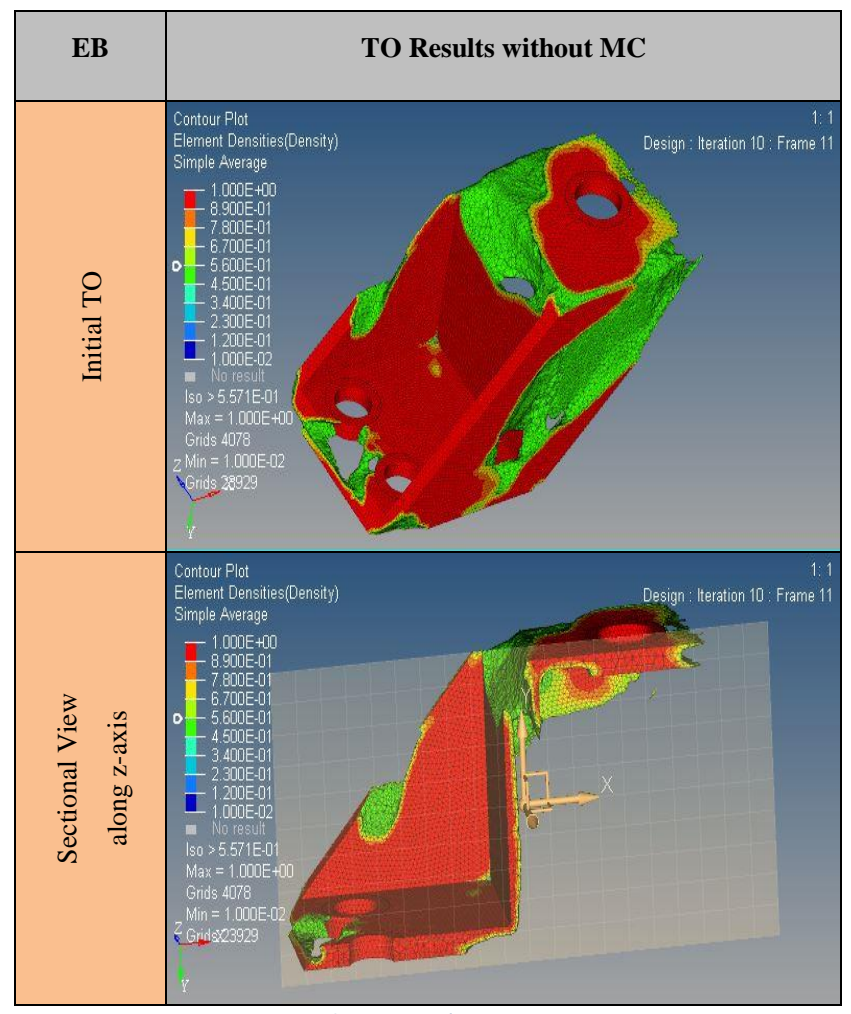

Figure 9. TO without $M C-E B$

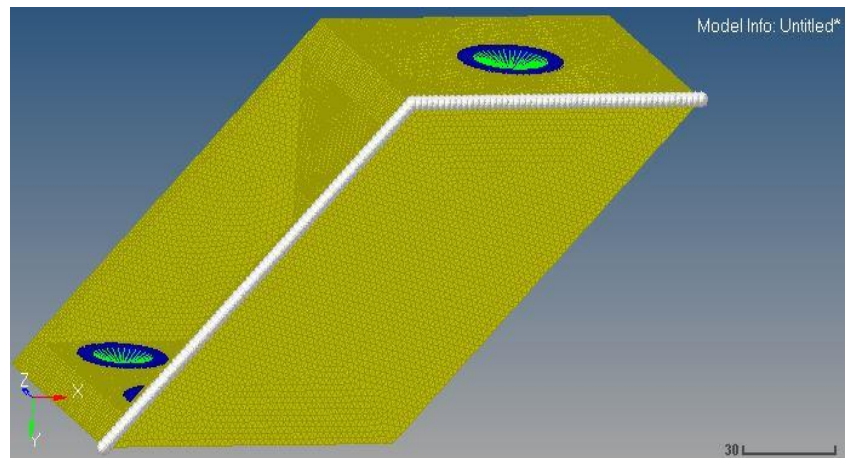

Figure 10. Extrusion Path - EB

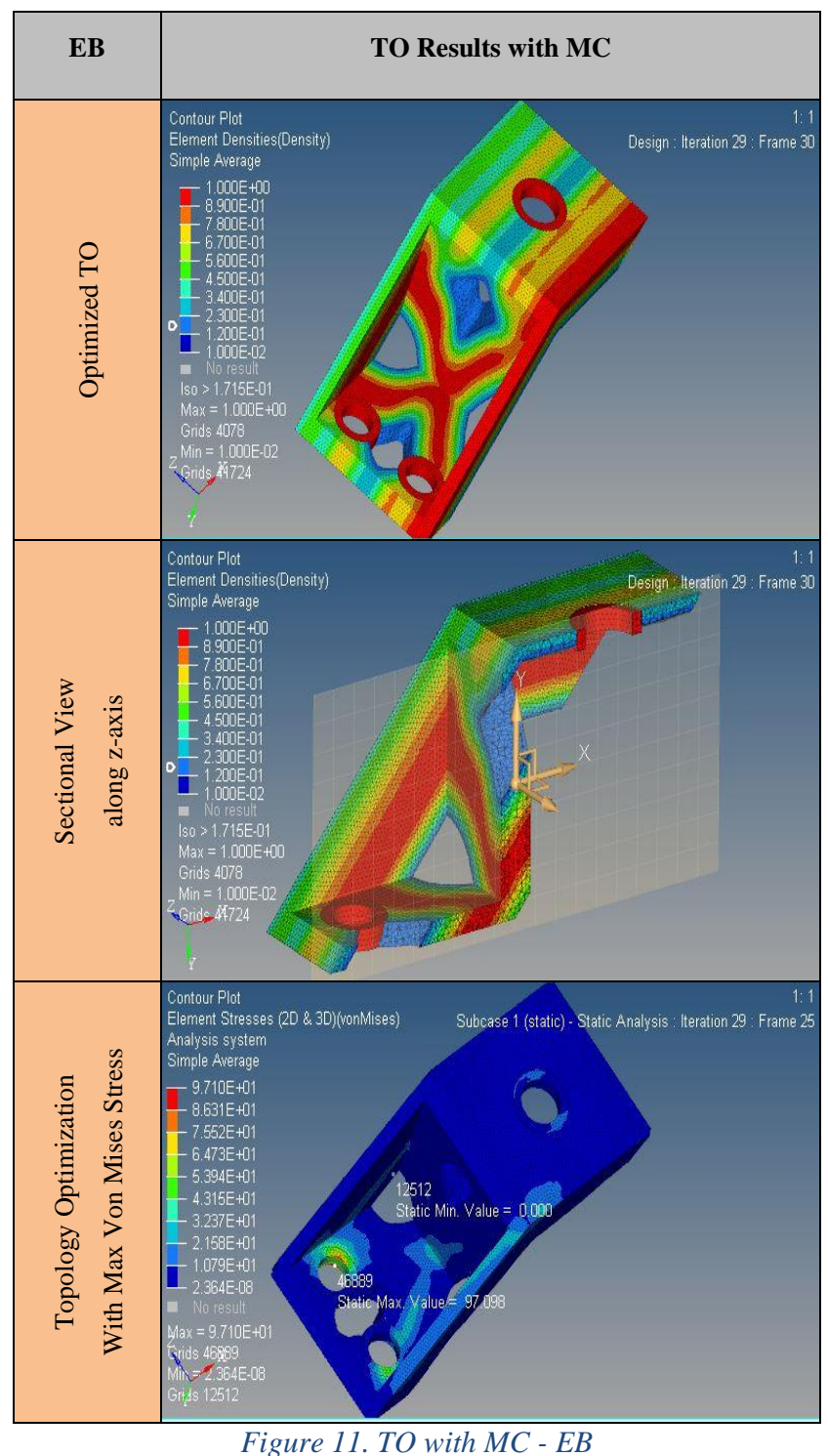

HB: Results obtained from simple TO show irregular shape at surfaces of the bottom and side walls while hidden cavities can also be seen along the arc length (Fig.12). Therefore, TC and EC need to be applied to obtain the desired results. Employment of TC with mindim $32 \mathrm{~mm}$ and extrusion path along the arc length (Fig.13) remove the undesired anomalies. Finally very nice results are obtained with max Von Mises Stress $21.6 \mathrm{~N} / \mathrm{m}^{2}$ (Fig.14). In addition, it is also noticed that removing cavities along the arc length, the overall weight is increased at large. 


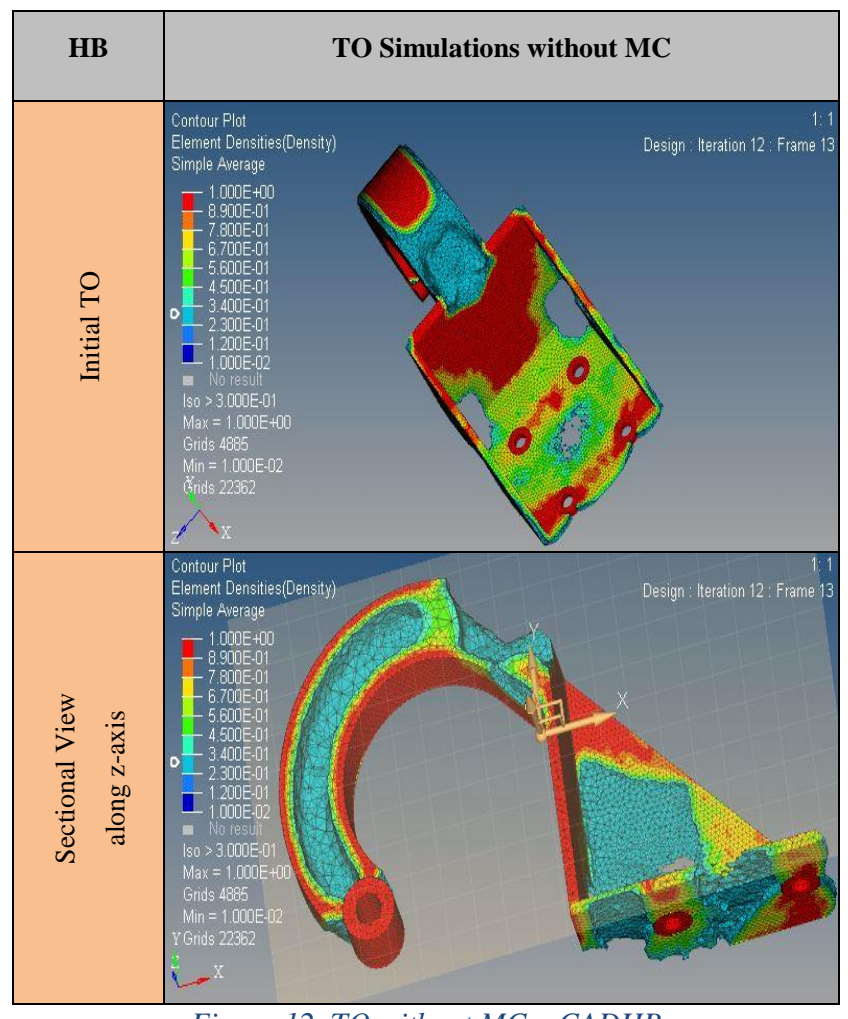

Figure 12. TO without $M C-C A D H B$

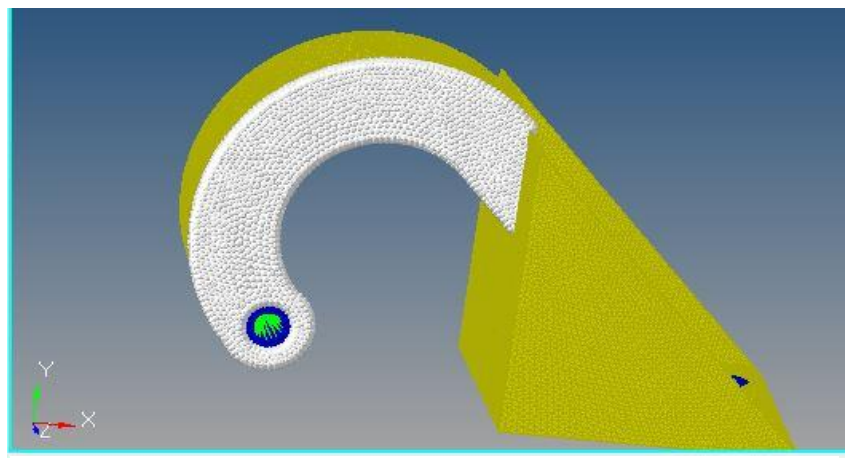

Figure 13. Extrusion Path - HB

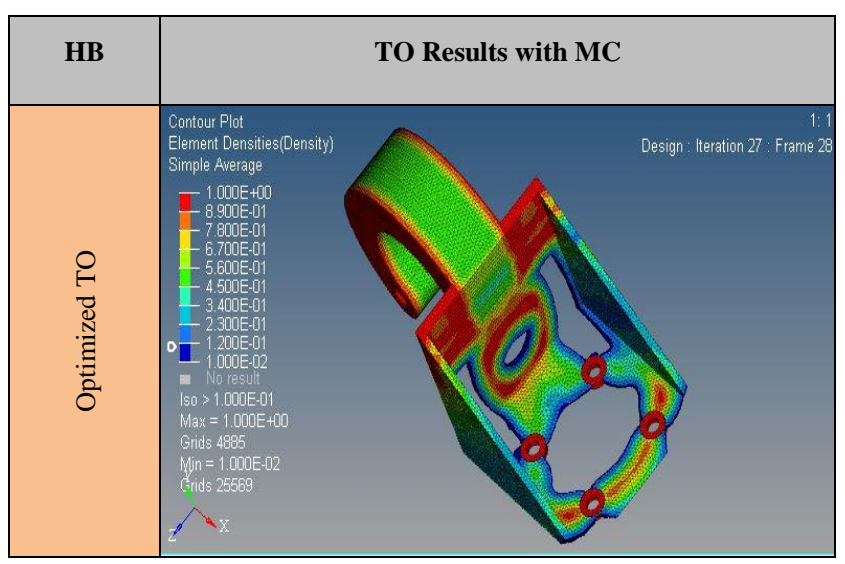

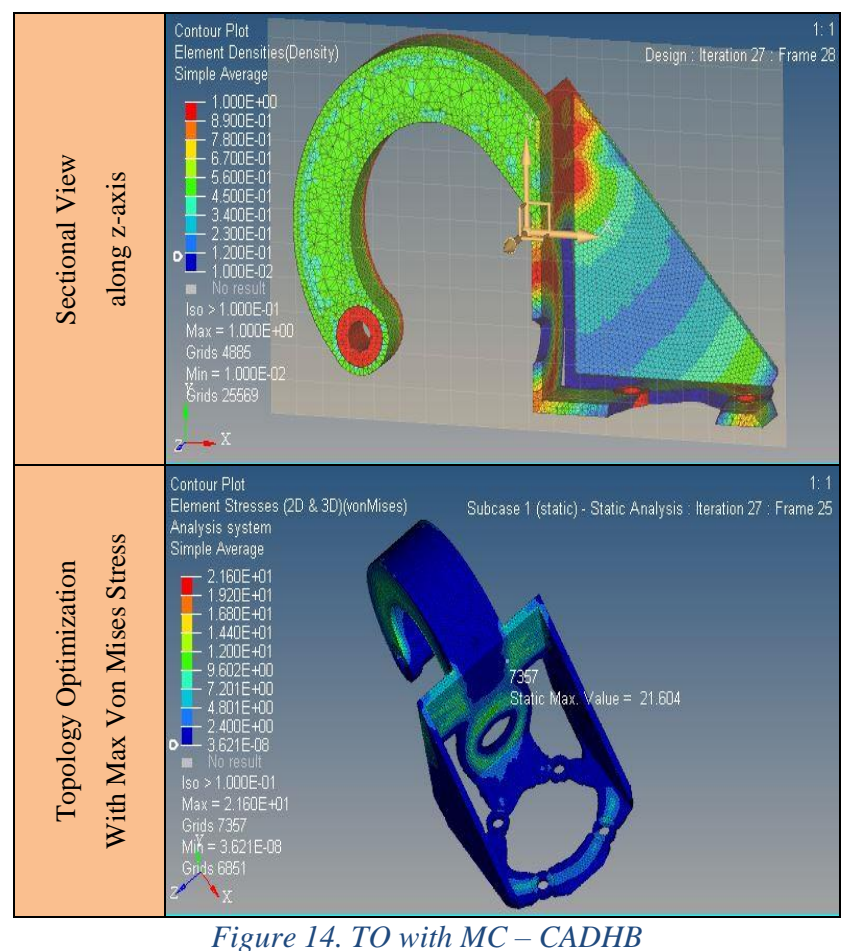

Finally, results obtained from both simple TO and TO with MC are summarized as Table. 3 and CAD models of the final optimized structures are obtained using OSSmooth tool of OptiStruct (Fig.15).

Table 3. Summary of the Results

\begin{tabular}{|c|c|c|c|c|c|c|c|}
\hline Structure & 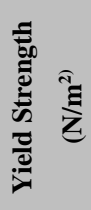 & 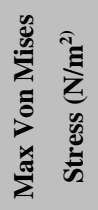 & है & 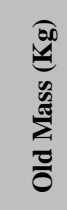 & 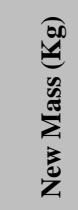 & 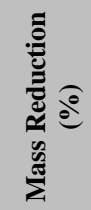 & 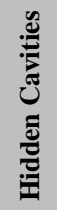 \\
\hline GPB & $4.6 \mathrm{e}^{8}$ & 0.277 & $>2.5$ & 0.72 & 0.36 & 50 & No \\
\hline EB & $4.6 \mathrm{e}^{8}$ & 97 & $>2.5$ & 0.39 & 0.27 & 32.16 & No \\
\hline $\mathrm{HB}$ & $4.6 \mathrm{e}^{8}$ & 21.6 & $>2.5$ & 2.26 & 1.5 & 33.6 & No \\
\hline
\end{tabular}




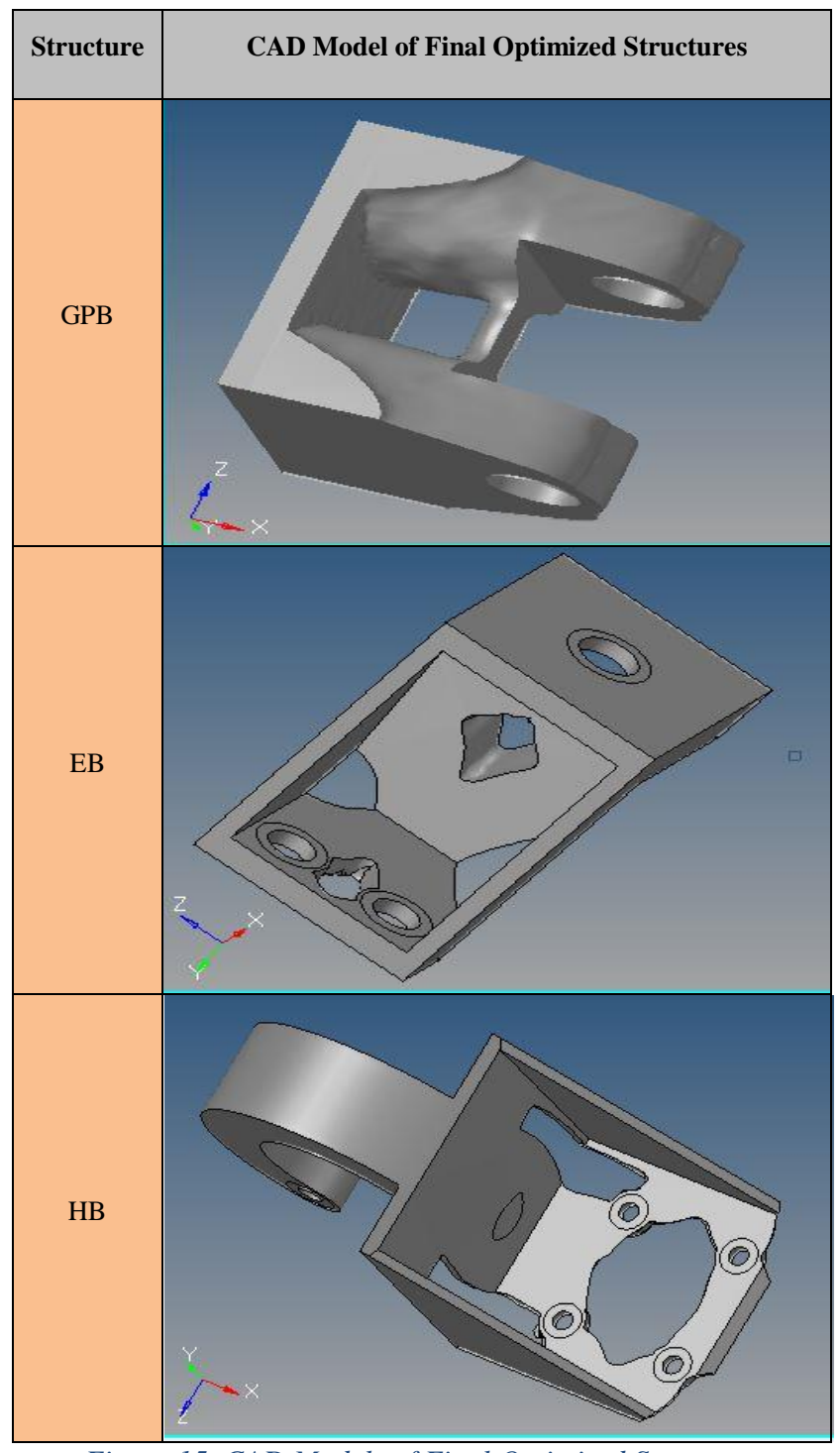

Figure 15. CAD Models of Final Optimized Structures

\section{CONSLUSIONS}

From the given analysis, it is concluded that employment of MC offers a great tradeoff between lightweight design and smooth / cavity free geometry but on the other hand it produces very simple geometries that can be manufactured very easily with $\mathrm{AM}$ or Casting techniques.

Furthermore, the geometrical features are so smooth that no further CAD optimization is required for smoothing the surfaces and only OSSmooth tool is enough to produce CAD models of the final optimized structures for manufacturing purpose.

\section{ACKNOWLEDGMENT}

We are collectively thankful to CEASAT Islamabad, Pakistan for sponsoring this conference paper.

\section{REFERENCES}

J.-H. Zhu, W.-H. Zhang, and L. Xia, "Topology Optimization in Aircraft and Aerospace Structures Design," Archives of Computational Methods in Engineering, vol. 23, no. 4, pp. 595622, 2015.

Fiebig, Sierk and Sellschopp, Jurgen and Manz, Holger and Vietor, Thomas and Axmann, K and Schumacher, Axel,"Future challenges for topology optimization for the usage in automotive lightweight design technologies," in Advances in Structural and Multidisciplinary Optimization-Proceedings of the 11th World Congress on Structural and Multidisciplinary Optimization, Sydney, Australia, 2015.

I. Durgun and A. R. Yildiz, "Structural Design Optimization of Vehicle Components Using Cuckoo Search Algorithm," Materials Testing, vol. 54, no. 3, pp. 185-188, 2012.

O. Zienkiewicz, R. Taylor, and D. Fox, "Computer Procedures for Finite Element Analysis," The Finite Element Method for Solid and Structural Mechanics, pp. 589-595, 2014.

A. University, "OptiStruct for Structural Analysis_Optimization," YouTube, 06-Apr-2015. [Online]. Available: https://www.youtube.com/watch?v=eBQju7kuhwo. [Accessed: 04-Sep-2019].

J. S. Arora, "Introduction to Optimum Design with MATLAB," Introduction to Optimum Design, pp. 413-432, 2004.

R. T. Haftka and Z. Gürdal, "Classical Tools in Structural Optimization," Elements of Structural Optimization Solid Mechanics And Its Applications, pp. 23-69, 1992.

S.-B. Jeong, S. Yoon, S. Xu, and G.-J. Park, "Non-linear dynamic response structural optimization of an automobile frontal structure using equivalent static loads," Proceedings of the Institution of Mechanical Engineers, Part D: Journal of Automobile Engineering, vol. 224, no. 4, pp. 489-501, Dec. 2010.

B.-S. Kang, G.-J. Park, and J. S. Arora, "A review of optimization of structures subjected to transient loads," Structural and Multidisciplinary Optimization, vol. 31, no. 2, pp. 81-95, Sep. 2006.

[10] T. Meinders, I. Burchitz, M. Bonte, and R. Lingbeek, "Numerical product design: Springback prediction, compensation and optimization," International Journal of Machine Tools and Manufacture, vol. 48, no. 5, pp. 499-514, 2008.

C. Ortmann and A. Schumacher, "Graph and heuristic based topology optimization of crash loaded structures," Structural and Multidisciplinary Optimization, vol. 47, pp. 839-854, Aug. 2013.

U. Schramm and M. Zhou, "Recent Developments in the Commercial Implementation of Topology Optimization," Solid Mechanics and Its Applications IUTAM Symposium on Topological Design Optimization of Structures, Machines and Materials, pp. 239-248, 2006.

M. P. Bendsøe and O. Sigmund, "Topology optimization: theory, methods, and applications,”Berlin: Springer, 2013.

G. I. Rozvany, "Topology optimization,"Topology Optimization in Structural and Continuum Mechanics, vol. 549, pp. 71, 2013. 
[15] Cavazzuti, Marco and Splendi, Luca and D'Agostino, L and Torricelli, E and Costi, Dario and Baldini, Andrea,"Structural Optimization of Automotive Chassis: Theory, Setup, Design," Structural and Multidisciplinary Optimization, pp. 1-3, 2011.

[16] M. Cavazzuti, A. Baldini, E. Bertocchi, D. Costi, E. Torricelli, and P. Moruzzi, "High performance automotive chassis design: a topology optimization based approach," Structural and Multidisciplinary Optimization, vol. 44, pp. 45-56, 2010.

Google Search. [Online]. Available: https://www.google.com/search?q=Altair+Engineering+,+Altair+H yperWorks, $+2017,+$ OptiStruct-

17.0+Users+Guide,+Altair+Engineering, + Troy, $,+M I,+2017 . \& s a=X$ \&ved=0ahUKEwiAi6PZ0LfkAhWMy4UKHSUuBG8QgwMILQ $\&$ biw $=1024 \& b i h=608$. [Accessed: 04-Sep-2019].

[18] M. Bici, G. B. Broggiato, and F. Campana, "Topological Optimization in Concept Design: starting approach and a validation case study," Lecture Notes in Mechanical Engineering Advances on Mechanics, Design Engineering and Manufacturing, pp. 289-299, Mar. 2016.

[19] T. Zegard and G. H. Paulino, "Bridging topology optimization and additive manufacturing," Structural and Multidisciplinary Optimization, vol. 53, pp. 175-192, May 2015.

[20] Lazarov, Boyan S and Wang, Fengwen and Sigmund, Ole,"Length scale and manufacturability in density-based topology optimization," Archive of Applied Mechanics, vol. 86, pp. 189-218, 2016.

[21] S. J. Heo, D. O. Kang, J. H. Lee, I. H. Kim, and S. M. H. Darwish, "Shape optimization of lower control arm considering multidisciplinary constraint condition by using progress meta-model method," International Journal of Automotive Technology, vol. 14, pp. 499-505, 2013.

[22] E. Holmberg, B. Torstenfelt, and A. Klarbring, "Stress constrained topology optimization," Structural and Multidisciplinary Optimization, vol. 48, pp. 33-47, Jan. 2013.

[23] M. Zhou, R. Fleury, Y.-K. Shyy, H. Thomas, and J. Brennan, "Progress in Topology Optimization with Manufacturing Constraints," 9th AIAA/ISSMO Symposium on Multidisciplinary Analysis and Optimization, Apr. 2002.

[24] S. Liang and Y. Zhang, "Digital Topology Optimization Design and Manufacturing Based on the Level Set Method," Modern Applied Science, vol. 5, 2011.

[25] Kim, J. Yoon and B. Kang, "Finite element analysis and modeling of structure with bolted joints," Applied Mathematical Modelling, vol. 31, pp. 895-911, 2007.

[26] Montgomery, Jerome," Methods for modeling bolts in the bolted joint," ANSYS User's Conference, Vol. 5, 2002. 